\title{
Assessment of the Rainfall Exceedance in Nigeria
}

\author{
A.O. Eruola ${ }^{1, *}$, A.A. Makinde ${ }^{2}$, G.A. Eruola ${ }^{3}$, K.O. Ayoola $^{4}$ \\ 1,2,4 Department of Water Resources Management, Federal University of Agriculture, Abeokuta, NIGERIA. \\ ${ }^{3}$ Department of Physics, Federal University of Agriculture, Abeokuta, NIGERIA.
}

\begin{abstract}
This study assessed rainfall extremes for agricultural overview in Nigeria using trend analysis and probability of exceedance expressed as normal for an average at 50\% exceedance, wet for greater than average $20 \%$ exceedance and dry for lower than average $80 \%$ exceedance. The annual rainfall trend indicated variability in the six geopolitical regions with North-East having the lowest range and South-South area with highest. The average monthly rainfall exceedance showed that all part of the Nigeria experienced rainfall more than $100 \mathrm{~mm}$ at all levels of probability. The rainfall exceedance time series indicated extremes as well as critical values of $20 \%$ and $80 \%$ exceedance conditions at many stations during the study period. The critical values of exceedances in dry occurrences are in short-time scales in Northern region while, wet exceedances occurrences for long time scales in South-East, South-West, North-Central and North-West. The study revealed periods of extreme rainfall of significant magnitude susceptible to crop failure in the different regions if reliable cropping management plans is not put in place.
\end{abstract}

Keywords: Extreme precipitation, variability, drought, flood, crop yield, climate extremes

\subsection{INTRODUCTION}

Rainfall is undoubtedly the most critical hydroclimatic variable that has profound effect on agricultural production and water resources management. Rainfall is not only important in Nigeria because of influence on agricultural calendar [1] as most agricultural production is basically rain fed, but also for its impact on food distribution [2], ground and surface water yield. For instance, the amount of rainfall that is normally received determines what types of agriculture activity that can be carried out, which crops can be cultivated in a region, ground water potentials and reservoir yield. This is because the two rainfall extremes have profound adverse effects on agricultural production and water supply potential. Rainfall anomalies are in form of natural hazards caused by a lower-than or more than average rainfall.

When this phenomenon occurs for the duration of a season or for extended periods of time, it creates insufficient or excessive conditions to supply human and environmental demands [3]. The insufficient rainfall in the form of drought is a temporary climate phenomenon that typically begins as a dry spell or a period of abnormally dry weather. In contrast, the excessive rainfall in form of flood is when land that is normally dry is submerged. Drought and flood, respectively, can alternatively be broadly defined as a temporary, recurring

*Corresponding author (Tel: +234 (0) 805735 4226)

Email addresses: layosky@yahoo.com (A.O.

Eruola), hakmak4u@yahoo.com (A.A. Makinde),

eruolagbenga@yahoo.com (G.A. Eruola),

ayoolakola1@yahoo.com (K.O. Ayoola) reduction or excessive precipitation in an area, and is considered as one of the most important climate change impacts on natural and socio-economic systems. Unlike the flood and other extreme events drought are economically and ecologically disruptive and its effects occur after long periods without precipitation, therefore it is difficult to objectively quantify its characteristics in terms of intensity, amplitude, duration and spatial extent [4 - 6]. In recent years, flood has become more intense and frequent than drought. However, drought has a negative impact on the socio-economic balance of the countries concerned. For example, in recent years the most developed nations had to limit water use for irrigation and domestic use [7]. It was reported that an increase in food price was caused by a simultaneous drought in USA and Russia [8-9]; furthermore, in 2011, a mass migration in the Horn of Africa was caused by drought [10], and in 2010, drought affected food production in large parts of China [11]. Mountain regions and the Mediterranean basin considered "hot spots" of climate change, are susceptible to drought situations and are heavily impacted by extreme events $[12,13]$.

The variability of rainfall and the pattern of extreme high or low precipitation has been established due to changes on both the global and the regional scales due to global warming [14-15] and also that over the coming decades, higher temperature and changing precipitation levels caused by climate change will depress crop yields in many countries [16]. Hence, if the moves to encourage agriculture to ensure food security will continue to gain ground and acceptability, information on rainfall trend and probabilities of its occurrence at a signified magnitude is vital for the design of water supply and supplemental 
irrigation schemes, the evaluation of alternative cropping and soil water management plans. Such information can also be beneficial in determining the best plant species and the optimum time of seeding. This is more so that, climate change has been noticed to cause variation in rainfall receipt per rain - day and consequently leading to progressive early retreat of rainfall and its associated decline in rainfall frequency in Nigeria [17]. It was further argued that climate change has caused a shift in the normal timing and length of wet and dry seasons [18], shift in the seasonal variability of weather and climate; and increase in the seasonal fluctuation of the water bodies. However, since rainfall variability is associated with variations in the mean state and other rainfall statistics on all spatial and temporal scales beyond that of individual precipitation events, then for the analysis of its variability, a long range of record is required. Much as long rainfall records are mostly available in many countries, little use is made of this information because of the cumbersome nature of the records [19]. However, Research into rainfall trend with food crop has been extensive in Nigeria, among such are those carried out by [18, 20 - 24].

Furthermore, there has been research into rainfall probabilities for different agro climatic regions. Among are $[25,26]$. It was also suggested that the rainfall at 80 per cent probability can safely be taken as assured rainfall [27], while that of 50 per cent probability is the medium limit for taking dry risk. Bearing in mind that rainfall distribution during crop growing season affects the national crop production security and also hydrological characteristic of the catchment area, this research aimed at analyzing the hydrological anomaly conditions, which are related to the effect of the absence or excess precipitation on water resources, in Nigeria on regional basis and to verify potential rainfall anomaly trends during a period of
30 years (1990-2019), in an ongoing climate change scenario.

\subsection{MATERIALS AND METHODS}

\subsection{Description of Study Area.}

The study was conducted in Nigeria, subdivided into six geopolitical zones with a marked climatic difference: South-west, South-East, South-South, NorthWest, North-Central and North-East (Fig. 1). Nigeria has a tropical climate with variable rainy and dry seasons, depending on location. It is hot and wet most of the years in the South-East but dry in the Southwest and farther inland. A savanna climate with marked wet and dry seasons prevails in the North and West, while a grassland climate with little precipitation is found in the far North [16]. In general, the length of the rainy season decreases from South to North. In the South the rainy season lasts from March to November, whereas in the far North it lasts only from mid-May to September. A marked interruption in the rains occurs during August in the South, resulting in a short dry season often referred to as the "August break." Precipitation is heavier in the South, especially in the South-East, which receives more than 3,000 $\mathrm{mm}$ of rain a year, compared with about $1,800 \mathrm{~mm}$ in the Southwest and South-South with annual ranges between $800 \mathrm{~mm}$ and $2000 \mathrm{~mm}$. Rainfall decreases progressively away from the coast; the far North receives no more than $500 \mathrm{~mm}$ a year [23]. The North central has annual rainfall rate varies from $1200 \mathrm{~mm}$ and $1500 \mathrm{~mm}$, while the Northwest receives more than $1,800 \mathrm{~mm}$ of rain a year. The annual rainfall is below $500 \mathrm{~mm}$ in the far North-East and $800 \mathrm{~mm}$ which last for only four months June September. Temperature and humidity remain relatively constant throughout the year in the South, while the seasons vary considerably in the North; during the

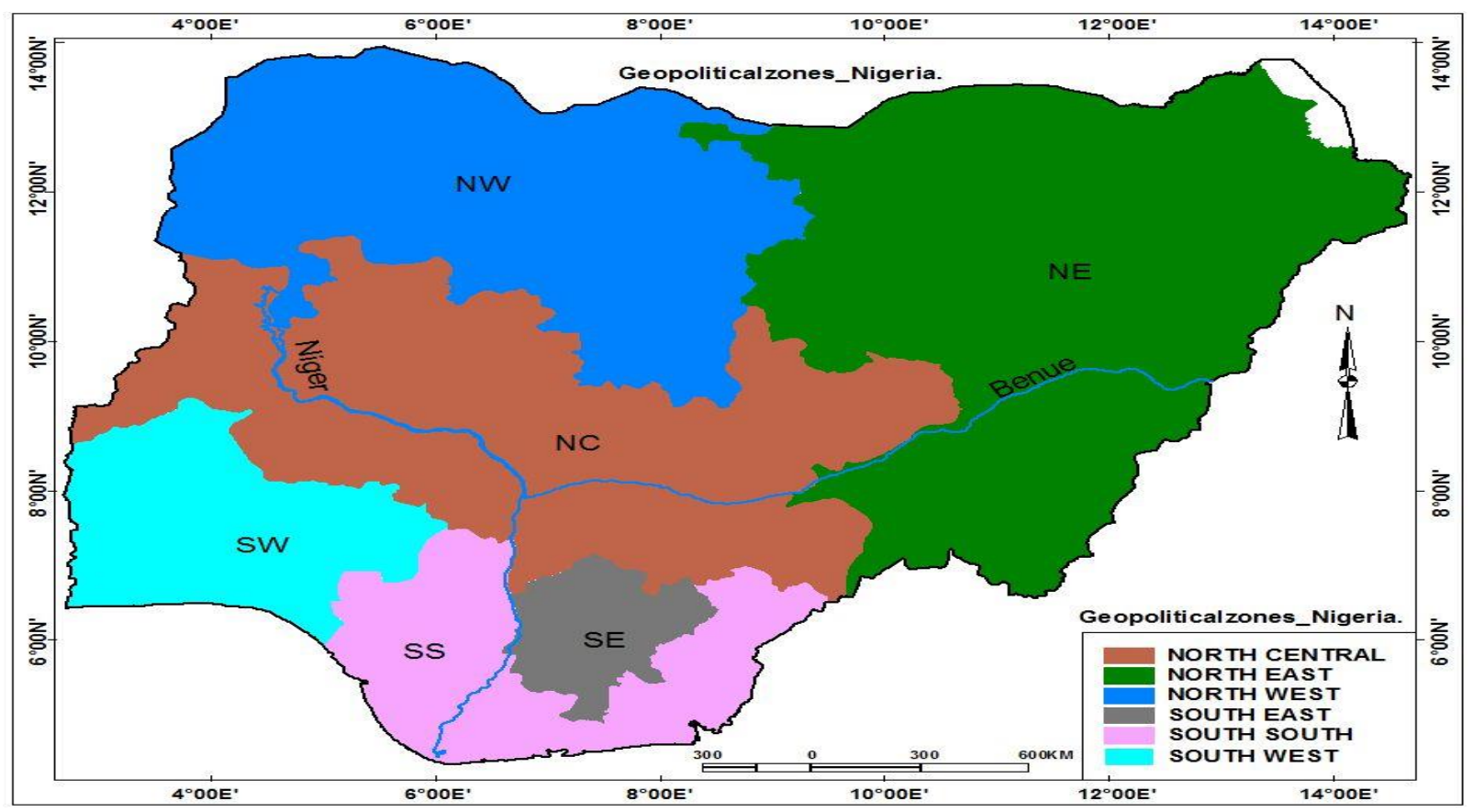

Figure. 1: Map of Nigeria and its geopolitical zones. 
Northern dry season the daily temperature range becomes great as well. Temperature and humidity remain relatively constant throughout the year in the South, while the seasons vary considerably in the North; during the Northern dry season the daily temperature range becomes great as well. On the coast the mean monthly maximum temperatures are steady throughout the year, remaining about $32{ }^{\circ} \mathrm{C}$ in South-west and about $33{ }^{\circ} \mathrm{C}$ in SouthSouth; the mean monthly minimum temperatures are approximately $22{ }^{\circ} \mathrm{C}$ for South-west and $20^{\circ} \mathrm{C}$ for SouthSouth. In general, mean maximum temperatures are higher in the North, while mean minimum temperatures are lower. In the North-Eastern, the mean monthly maximum temperature may exceed $38^{\circ} \mathrm{C}$ during the hot months of April and May, while in the same season frosts may occur at night. The humidity generally is high in the North, but it falls during the harmattan, which blows for more than three months in the North but rarely for more than two weeks along the coast.

\subsection{Meteorological data}

Monthly and annual weather data from selected stations in the six geopolitical zone were considered for all stations during the period 1990-2019, which is the accepted climatological standard 30-year period (WMO, 2017). The data were collected from Nigeria Meteorological Services (NIMET). Shaki, Oshogbo, Ondo and Ijebu-ode were the stations considered in Southwest, while Sokoto, Kaduna and Kano were selected in North West; Ilorin, Abuja and Markudi were stations selected in North Central and Onitsha, Owerri and Enugu were used for South-East. Furthermore, Warri, Port Harcourt and Uyo were selected for South-South while Bauchi, Maiduguri and Yola were used for Northeast. These are uniformly distributed in the region (Fig. 1)

\subsection{Method of probability of exceedance and return period estimation}

Estimates of rainfall depths (XP) expected for a specific probability during monthly and yearly reference period is indicated as the likelihood that the actual rainfall during that period will be equal to or higher than the estimated rainfall depth. This refers to the minimum amount of rain one can rely on during the reference period, and therefore is often denoted as dependable rainfall in irrigation sciences. The probability of exceedance refers to the probability of the occurrence of a rainfall depth greater than some given XP value. The probability of exceedance $(\mathrm{P})$ is expressed as a fraction (on a scale ranging from zero to one) or as a percentage chance with a scale ranging from 0 to 100 percent. In this study, rainfall data of normal, wet and dry years are used. An estimate of the rainfall data was obtained by computing and plotting probabilities from rainfall records. The steps involved are:

1. Tabulate yearly rainfall totals for a given period.
2. Arrange data in descending order.

3. Tabulate plotting position according to:

$$
F a=100 \times \frac{m}{(N+1)}
$$

Where: $\mathrm{N}=$ number of records

$\mathrm{m}=$ rank number

$\mathrm{Fa}=$ plotting position

4. Plot values on log-normal scale and obtain the logarithmic regression equation.

5. Calculate year values at 20,50 and $80 \%$ probability

6. Determine monthly values for the dry year according to the following relationship:

$$
P_{i d r y}=P_{i a v} \times \frac{P_{d r y}}{P_{a v}}
$$

Where: $P_{\text {iav }}=$ average monthly rainfall for month i

$P_{\text {idry }}=$ monthly rainfall dry year for month $\mathrm{i}$

$P_{a v}=$ average yearly rainfall

$P_{d r y}=$ yearly rainfall at $80 \%$ probability of exceedance.

Similarly, values for normal and wet years can be determined.

In flood prediction and rain fed agriculture, the amount of rainfall that can be expected in four out of five years is more important than the mean rainfall. The procedure for the determination of dry, normal and wet weather conditions is as follows:

1. The weather condition in a period is called dry if the rainfall received during that period will be exceeded in 4 out of 5 years, i.e., having a probability of exceedance of $80 \%$.

2. The weather in a period is normal, if the rainfall received during that period will be exceeded in 1 out of 2 years, i.e., having a probability of exceedance of $50 \%$.

3. The weather condition in a period is called humid if the rainfall received during that period is exceeded 1 out of 5 years, i.e., having a probability of exceedance of $20 \%$.

While $20 \%$ probability of exceedance representing a wet year is taken as the assured or dependable rainfall for flood activities used in the design of drainage system capacity, the $80 \%$ probability of exceedance representing a dry year is taken as the assured or dependable rainfall for drought useful in the design of irrigation system capacity.

The return period (also called the recurrence interval) TX is the period expressed in number of years in which the annual observation (rainfall) is expected to return. It is the reciprocal value of the probability when 
expressed as a fraction; $20 \%$ dependable rainfall $(\mathrm{PX}=$ $0.20)$ has a return period of $\left(\frac{1}{0.20}=\right)$ 5years.

\subsection{RESULTS}

\subsection{Rainfall trends in Nigeria}

The annual rainfall trend in Nigeria as presented in Figure 2 indicated that there was variability in total rainfall in the six geopolitical regions and in Nigeria at large. The average range of annual rainfall in Nigeria varies from $500 \mathrm{~mm}$ in the Northeast to 3000 in South-South Nigeria. The annual rainfall was higher at the Southern region than the Northern region. The Southwestern part has the lowest range of rainfall ranging from $800 \mathrm{~mm}$ to $1600 \mathrm{~mm}$ in the Southern part of Nigeria, while the South-South area has the highest range between $2000 \mathrm{~mm}$ and $3000 \mathrm{~mm}$. However, the rainfall trend in the South-East ranged between $1200 \mathrm{~mm}$ and $2500 \mathrm{~mm}$. On the other hand, for the Northern part of Nigeria, it was obvious from Figure 2 that the North-cental part has the highest range of rainfall, $700 \mathrm{~mm}$ to $1430 \mathrm{~mm}$ followed by the North-west area $600 \mathrm{~mm}$ and $1000 \mathrm{~mm}$. The North-East part of Nigeria has the lowest rainfall trend, with the range between $500 \mathrm{~mm}$ and $800 \mathrm{~mm}$.

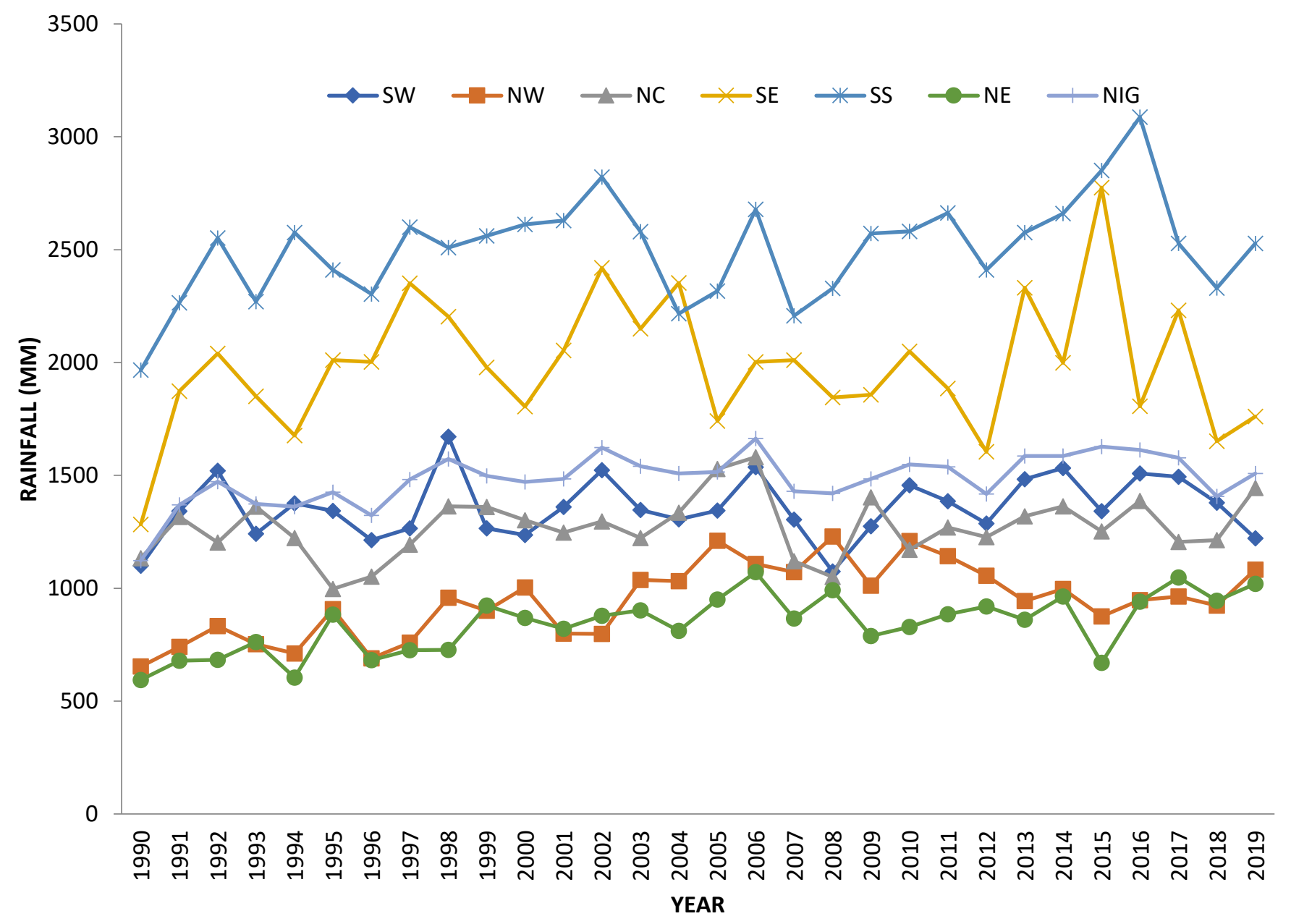

Figure. 2: Rainfall trend in Nigeria

The patterns of distribution of rainfall trend in all states considered in the six geopolitical zones of Nigeria were similar. However, there was variation in their annual magnitudes and ranges. In Southwestern (SW) Nigeria as presented in the panel of Figure 3 with SW indication inscribed, Ondo state has the highest total rainfall peaks while the lowest total was observed in Shaki. The highest mean annual rainfall observed in the region was $1500 \mathrm{~mm}$ while the lowest was $1000 \mathrm{~mm}$. When the rainfall trend was considered for the South-Eastern (SE) region as shown in figure 3, it was observed that more rainfall total peaks were obvious in Owerri, though a singular highest peak of $4000 \mathrm{~mm}$ was noticed in Onitsha in the year 2015 .
The lowest annual rainfall values were found in Enugu with the least valve of $800 \mathrm{~mm}$ in the year 1990 similar to a singular lowest value obtained in Onitsha in 2012. In general, the range of rainfall total is between $800 \mathrm{~mm}$ to $3000 \mathrm{~mm}$ in Southeastern Nigeria.

Meanwhile, the investigation into annual rainfall trend of the South-South (SS) region of Nigeria as observed in panel shows that Warri has several high peaks, with a noticeable peak of $4000 \mathrm{~mm}$ in year 2016 and also a noticeable drought of $800 \mathrm{~mm}$ in the year 2018 were seen in Uyo, Akwa- Ibom State. Generally, the range of total rainfall in South-South Nigeria is between 1200 $\mathrm{mm}$ to $3000 \mathrm{~mm}$. 


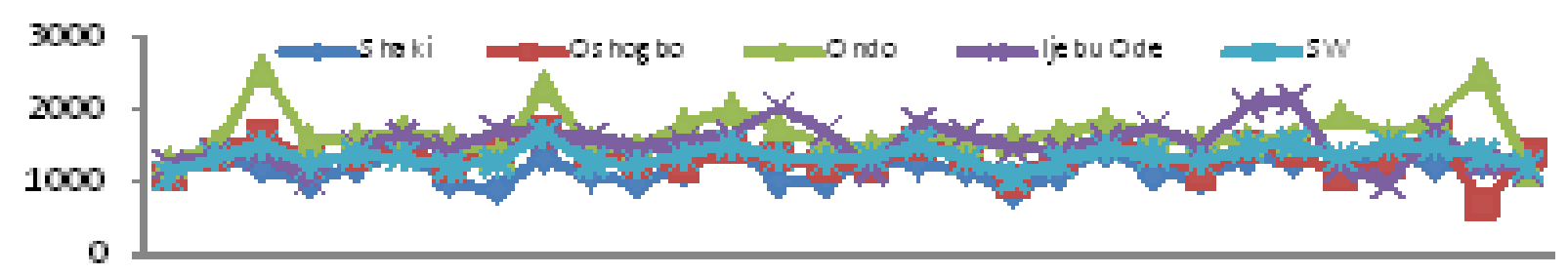

199019921994199619982000200220042006200020102012201420162018

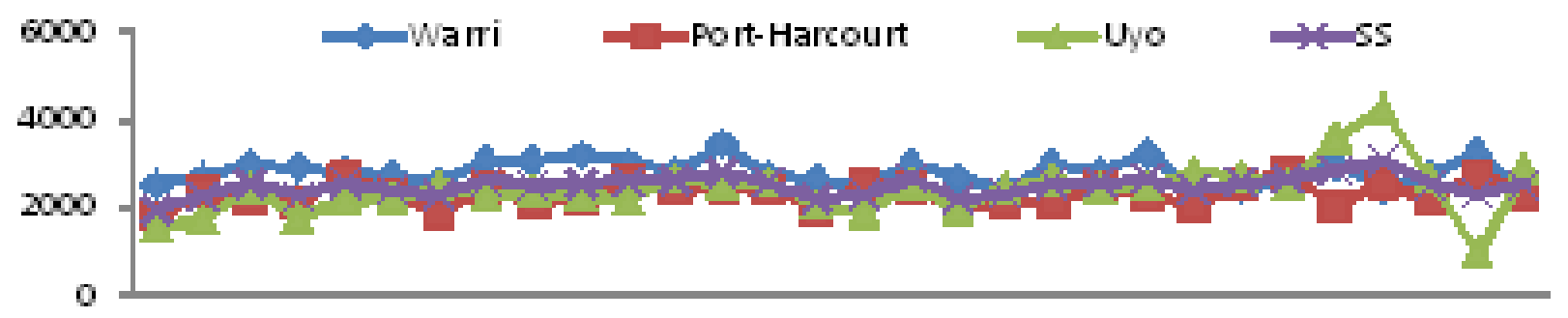

199019921994199619982000200220042006200020102012201420162018

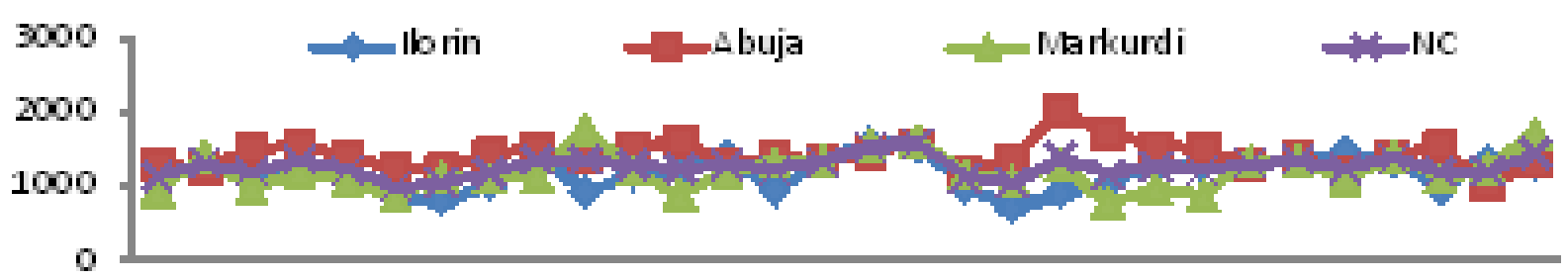

199019921994199619902000200220042006200020102012201420162016

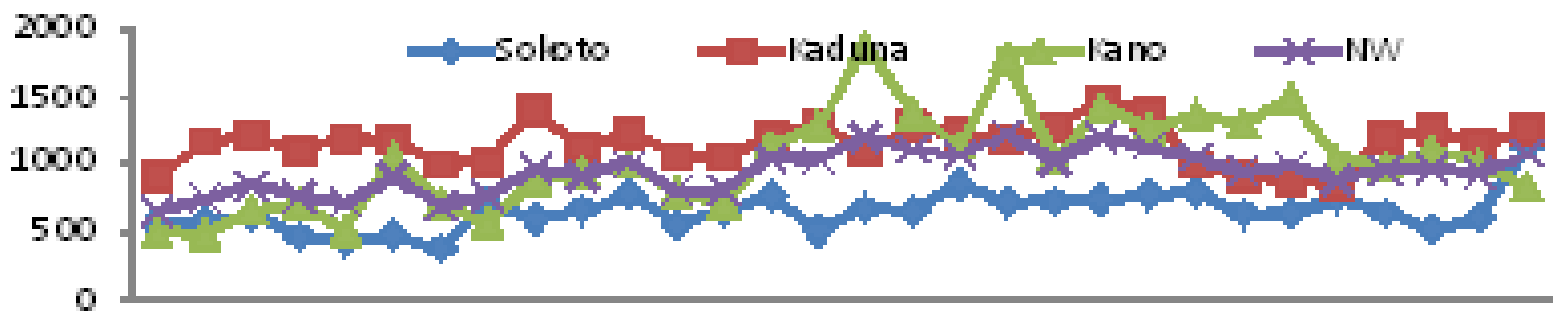

199019921994199619902000200220042006200020102012201420162016

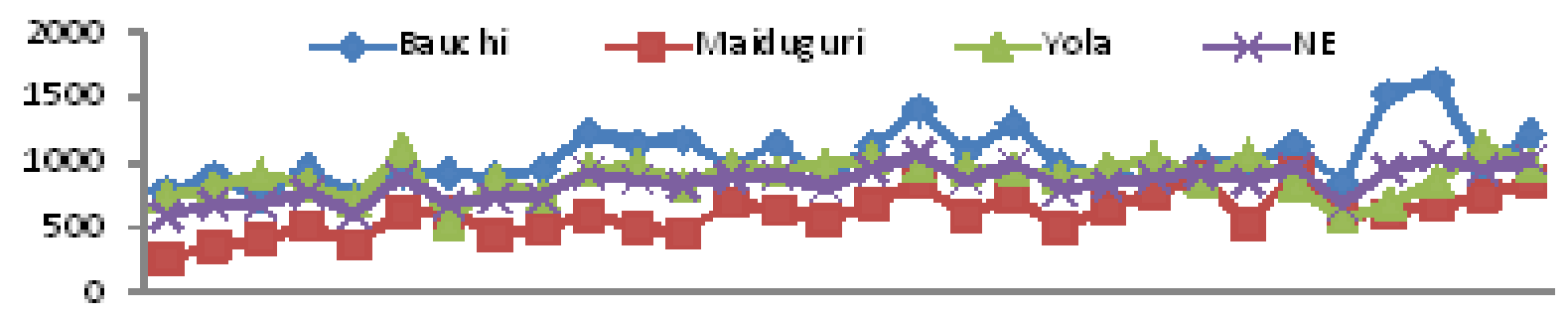

199019921994199619962000200220042006200020102012201420162018

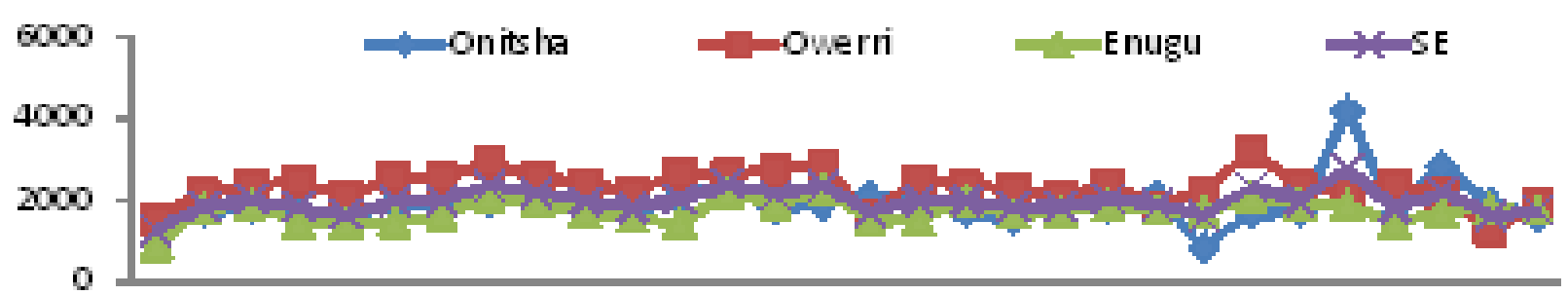

$19901992199419961998200020022004200620002010 \quad 2012201420162018$

YEAR

LEGEND: $S W=$ SOUTHWEST $;$ SE $=$ SOUTHEAST $;$ SS $=$ SOUTH-SOUTH $;$ NC $=$ NORTH CENTRAL; NW $=$ NORTHWEST; NE = NORTHEST

Figure. 3: Rainfall trend in the six geopolitical zones of Southwest Nigeria 
The investigation of annual rainfall trend in North central (NC) Nigeria as presented also in Figure 3 indicated that the highest total rainfall peaks are found in Abuja with the height of $2000 \mathrm{~mm}$ in the year 2009 while the lowest was in Ilorin with $700 \mathrm{~mm}$ in year 2008. The average total rainfall in North central is between $1000 \mathrm{~mm}$ and $1500 \mathrm{~mm}$. In the Northwestern region (NW) of Nigeria, Sokoto state exhibited the lowest total annual rainfall with the value at $350 \mathrm{~mm}$ while the highest of $1650 \mathrm{~mm}$ was observed in Kano. The range of average rainfall over Northwestern Nigeria was between $600 \mathrm{~mm}$ and $1000 \mathrm{~mm}$.

Further, in the investigation into Northeast Nigeria as presented in Figure 3, it was observed that throughout the experimental years assessed, Bauchi experienced the highest peak of rainfall of $1600 \mathrm{~mm}$ in 2017, while consecutively low rain rainfall of $250 \mathrm{~mm}$ was obvious in Maiduguri in the Eastern part of Nigeria. In general, however, the average rainfall range in the area lies between $500 \mathrm{~mm}$ and $1000 \mathrm{~mm}$.

\subsection{Monthly variation in rainfall exceedance in Nigeria}

The probability of exceedance of average monthly values of rainfall for a period of 30 years in the six geopolitical zones of Nigeria as presented in Figures 4 indicated that rainfall exceeded normal average value in all locations. The result shows that probability of receiving rainfall more than $100 \mathrm{~mm}$ was experienced at all probability level $20 \%$ (wet), 50\% (normal) and $80 \%$ (dry) between April and October in all Southern Nigeria area and between June and September in the Northern part of the geopolitical zones. Regarding the Southern part of the country, it was observed that monthly rainfall experiences double peaks of with synonymous break in August, whereas the Northern area exhibits a singular peak.

The highest value of normal rainfall peak value of $350 \mathrm{~mm}$ was observed in South-South in July while the lowest peak value of $200 \mathrm{~mm}$ was observed in North central and Southwest in June. Furthermore, the peak of exceeding $500 \mathrm{~mm}$ dry months and $650 \mathrm{~mm}$ wet months were observed in Northwest in August. This implies that there were relatively abnormal wet and dry periods during the 30 years of study that is expected to affect crop production especially when such moisture condition occurs during the critical moisture requirement stage of growth of the crop.


Figure 4: Probability of exceedance of average monthly rainfall in the six geopolitical zones 
It was also observed that the monthly average peak was $650 \mathrm{~mm}$ in Northwest while at $20 \%$ probability (wet) and the monthly average rainfall peak was $500 \mathrm{~mm}$ at $80 \%$ probability (dry) in August. Whereas an average peak of $400 \mathrm{~mm}$ in South-South at $20 \%$ probability and $350 \mathrm{~mm}$ at $80 \%$ was obvious in July, while in the South-East average peak of $300 \mathrm{~mm}$ at $20 \%$ probability and $250 \mathrm{~mm}$ at $80 \%$ in September. The probability of exceedance as observed in Figure 4 further shows that monthly average peak was $250 \mathrm{~mm}$ in North-East while at $20 \%$ probability (wet) and the monthly average rainfall peak was $200 \mathrm{~mm}$ at $80 \%$ probability (dry) in August. On the other hand, monthly average peak was $250 \mathrm{~mm}$ in Southwest while at $20 \%$ probability (wet) and the monthly average rainfall peak was $200 \mathrm{~mm}$ at $80 \%$ probability (dry) in September. Though like in Southwest, the monthly average peak at $20 \%$ and $80 \%$ probability in Southwest and North central were similar having an average of $250 \mathrm{~mm}$ at $20 \%$ probability (wet) and $200 \mathrm{~mm}$ at $80 \%$ probability (dry), but on the contrary, the exceedance occurred in September.

\subsection{Total rainfall probability of Exceedance in Nigeria}

The annual probability of exceedance for the six geopolitical zones of Nigeria showed no homogeneous trend (Fig. 5). The series of annual rainfall trend showed critical anomaly in annual probability of exceedance of average peak at 20\% (wet) in South-East, South-west, North central and North-west and $80 \%$ probability (dry) all the Northern region. The period with the critical consecutive wet years were within 1997 to 2014, a total of 11 years, this agreed with the findings of NEMA, (2013), Jimoh, (2014) and Alabelewe, (2014) while the period with critical consecutive dry years were from 1990 to 1996,5 years. The average duration of the wet period as expected was more in the Southern part of Nigeria than the Northern part.

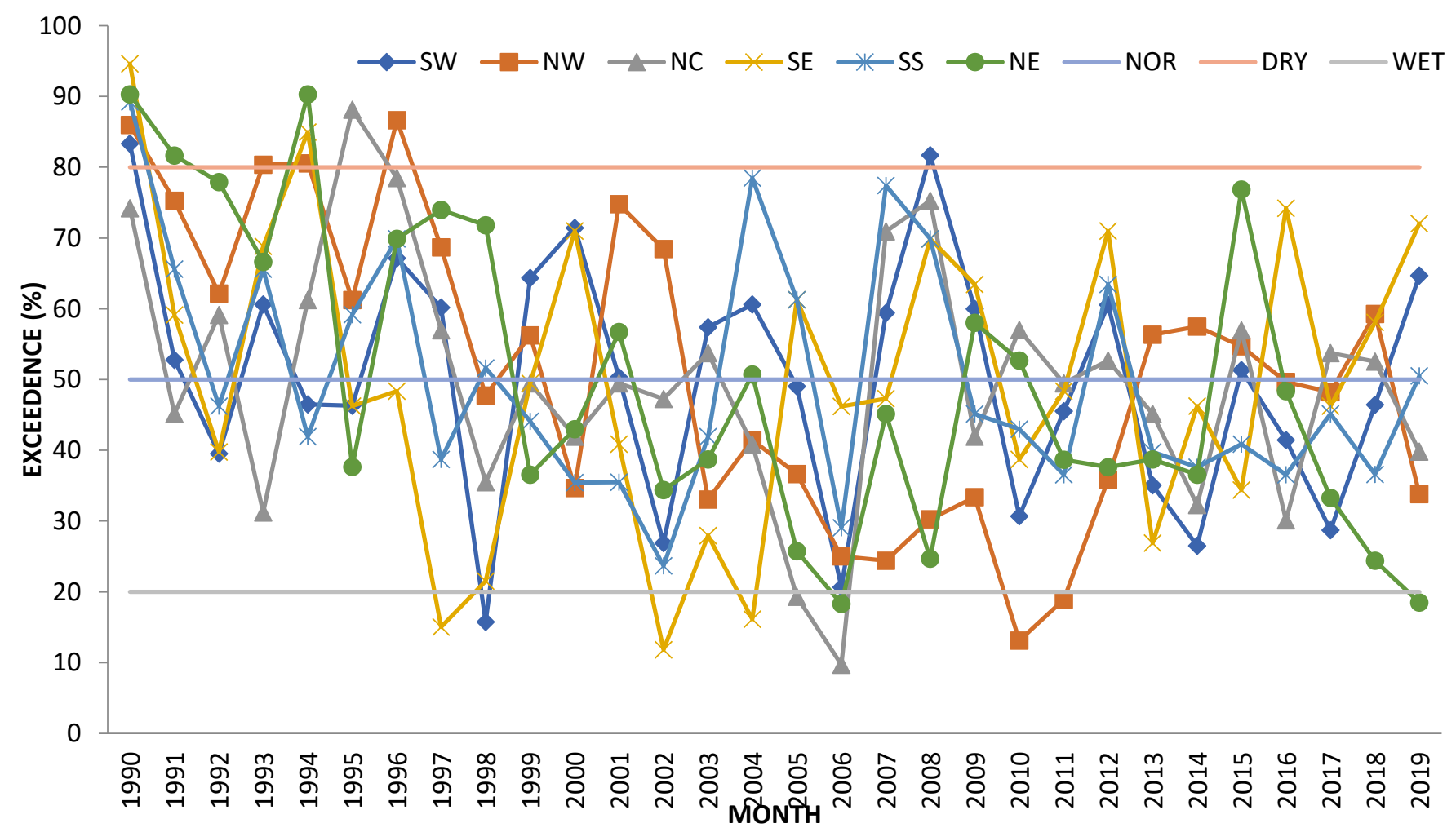

Figure 5: Exceedance probability values for the six geopolitical zone of Nigeria

\subsection{Regional total rainfall probability of Exceedance in Nigeria}

The annual probability of exceedance for Southwest (SW) Nigeria showed homogeneous trend with alternating wet and dry exceedances (Fig. 6). The series of annual rainfall trend in the Southwest region does not only showed exceedances above normal at average peak of both $20 \%$ (wet) and $80 \%$ probability (dry) but also a critical anomaly above the exceedances. The period with the exceedances and critical exceedances for both wet and dry were consecutive in series of three yearly average all through the selected years for the analysis. Meanwhile, the annual probability of exceedance for South-Eastern (SE) and South-Southern (SS) Nigeria does not exhibit homogeneous trend of wet and dry exceedances $\left(1^{\text {st }} \& 3^{\text {rd }}\right.$ panel of Figure 6). The series of annual rainfall trend in the South-Eastern and South-Southern region showed both exceedances above normal (50\%) annual probability of $20 \%$ (wet) and $80 \%$ probability (dry) and a critical anomaly above the exceedances. The period with the exceedances and critical exceedances were highly clustered as from the 2002 to 2019 for both regions. 




$199019921994199619 \% 2000200220042006200620102042201420162048$



199019921994199619982000200220042006200620102012201420162013

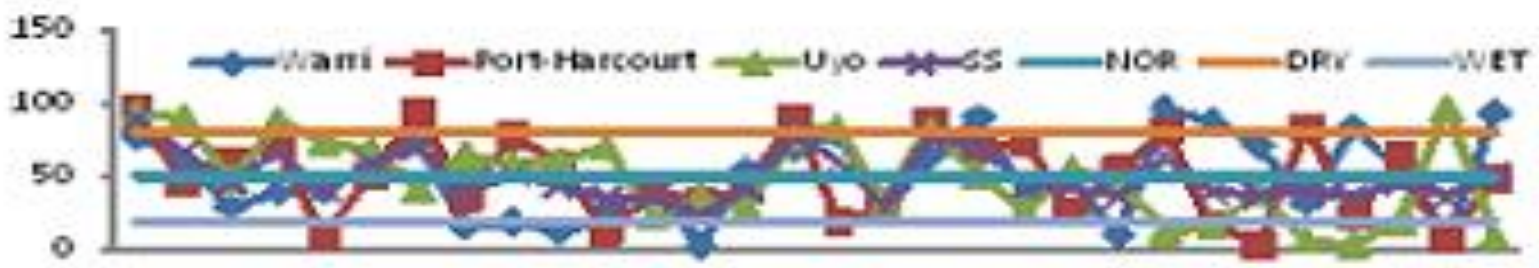

19901992199419961998200020022004200620062010 2012 2014 2016 2018

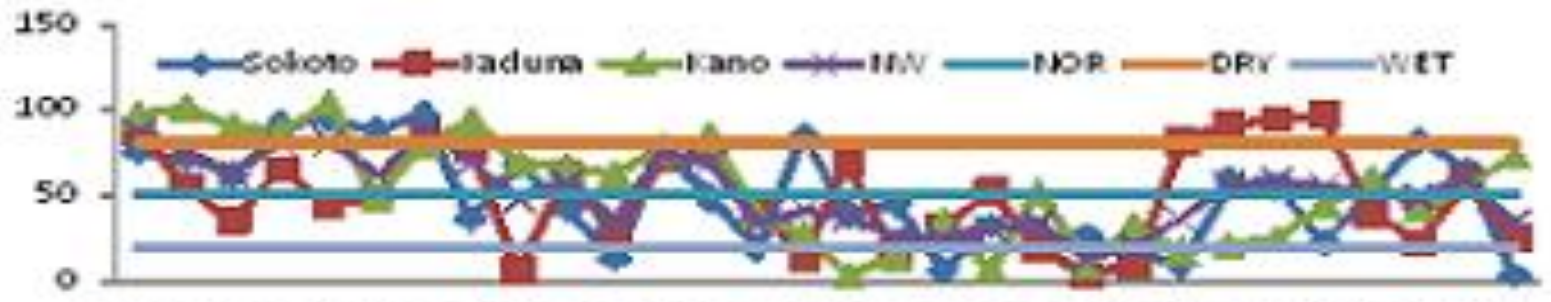

190019921994199619942000200220043006200620402042204420462048

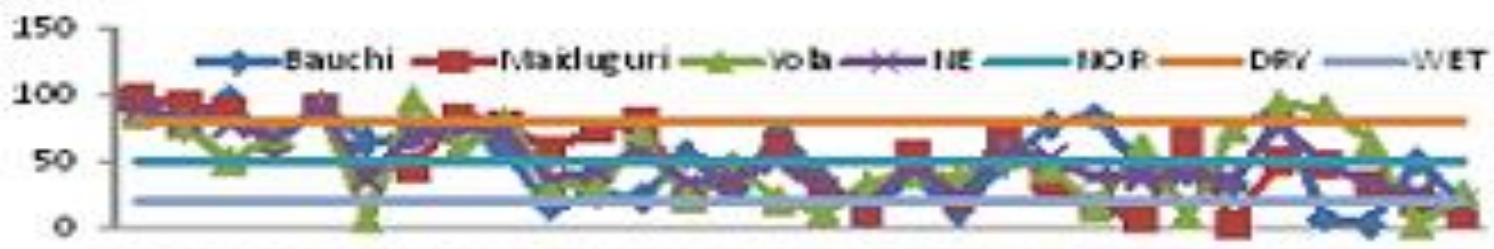

199019921994199619982000200220042006200620102042201420162018

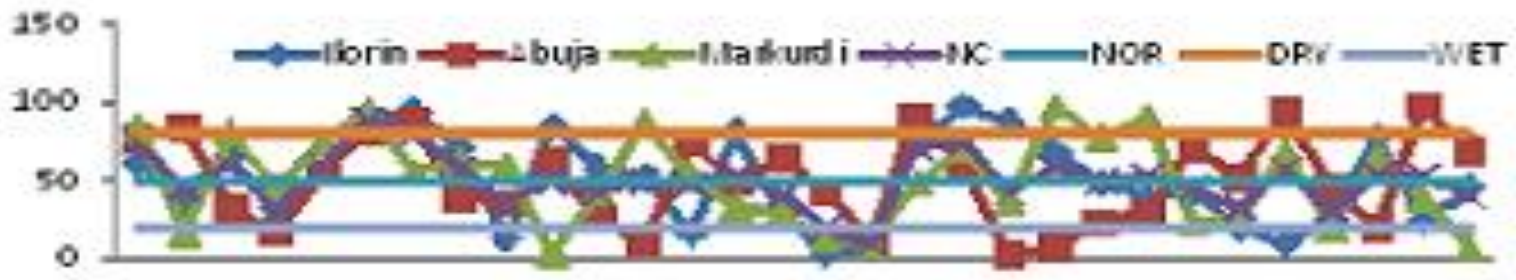

199019921994199619902000200220042006200620402012201420162018

\section{YEAR}

LEGEND: SW = SOUTHWEST; $S E=$ SOUTHEAST; SS = SOUTH-SOUTH; NC = NORTH CENTRAL; NW= NORTHWEST; NE = NORTHEST; NOR = NORMAL

Figure 6: Exceedance probability values for the stations within each of the six geopolitical zone of Nigeria

On the other hand, the annual probability of exceedance for North-western (NW) and North-Eastern (NE) Nigeria showed similar trend in wet and dry exceedances of rainfall $\left(4^{\text {th }} \& 5^{\text {th }}\right.$ panel of Fig. 6). The series of annual rainfall trend in both regions showed both exceedances above normal annual probability $(50 \%)$ of 
$20 \%$ (wet) and $80 \%$ probability (dry) and also a critical anomaly above the exceedances. The period with the wet exceedances and critically wet exceedances were highly clustered within the 1998 to 2019 (11 years), whereas the years before (1990 to 1997 i.e., 7 years) for both regions were in the dry exceedance range.

Regarding North-central (NC) region of Nigeria, the annual probability of exceedance rainfall trend showed both wet and dry exceedances $\left(6^{\text {th }}\right.$ panel in Fig. 6 ). The series of annual rainfall trend in the region, like in other regions showed both exceedances above normal annual probability $(50 \%)$ of $20 \%$ (wet) and $80 \%$ probability (dry) and also a critical anomaly above the exceedances. However, in the period between 1990 and 1994, there was no pronounced critical exceedance observed but more of $80 \%$ probability (dry) and critically dry were obvious between 2007and 2019.On the contrary, $20 \%$ probability (wet) and critically wet were observed between 1998and 2010.

\subsection{DISCUSSION}

The trend analysis of rainfall anomaly in six geopolitical zones was conducted using probability of exceedance series of 3 selected stations in each region, during the period 1990-2019. The similarities and differences were detected between the six environments. The rainfall and the exceedance trends were well defined with overwhelming variation in all regions. In particular, the annual rainfall variation was obvious with conspicuously higher values at the Southern region than the Northern region. The highest rainfall range is observed in the South- South area while the lowest range is found in the North-East. It has been reported by [28-30] that rainfall variability affects the production of traditional crops, increase incidents crop diseases, and causes drastic reductions in soil fertility in West Africa. This observation suggested the basis for recommending that a lot more effort must be done to improve crop production in the Northern region because of less rainfall variability compared to the Southern part. This strategy can help increase crop production, food security, and availability, more so that majority of food production in Nigeria is from the Northern part.

Meanwhile, the probability of exceedance of average monthly values of rainfall for a period of 30 years in the six geopolitical zones of Nigeria indicated that rainfall exceeded normal average value in all locations. It was obvious that probability of receiving rainfall exceeding $100 \mathrm{~mm}$ was experienced at all probability level normal $(50 \%)$, wet $(20 \%)$ and dry $(80 \%)$ between April and October in all Southern Nigeria area and between June and September in the Northern part of the geopolitical zones. This agreed with [31] that suggested that a short rainy season is experienced between March and May and much more variable rainfall periods between June and September in part of Africa. This explained the reason for growing season rainfall variability factor in the form of normal as well as climate extremes 'wet and dry' being the consequence for the variance of yield anomalies experience in the regions. It was obvious that crops produced in the Northern area suffered production loss due to insufficient rainfall accessible duration as suggested by [17] in his work, where he explained that during the long periods with normal and above normal rainfall, crop yield sensitivity tends to be weak while during the years with unusually low rainfall, crop yield sensitivity becomes more pronounced in arid region of Nigeria.

Regarding the Southern part of the country, it was observed that monthly rainfall experiences August break within two peaks, whereas the Northern area exhibits a singular peak. The highest value of normal rainfall peak value of $350 \mathrm{~mm}$ was observed in South-South in July while the lowest peak value of $200 \mathrm{~mm}$ was observed in North central and Southwest in June. Furthermore, the peak of exceeding $500 \mathrm{~mm}$ dry months and $650 \mathrm{~mm}$ wet months were observed in Northwest in August. This implies that there were relatively abnormal wet and dry periods which will affect crop production especially when such moisture condition occurs during the critical moisture requirement stage of growth of the crop. Hence, concerted political and practical action to conserve water is necessary to minimize the impact of future drought, such as appropriate water management policies, and climate-smart agriculture practices [32]. It was also further observed that the monthly average peak was 650 $\mathrm{mm}$ in Northwest while at $20 \%$ probability (wet) and the monthly average rainfall peak was $500 \mathrm{~mm}$ at $80 \%$ probability (dry) in August.

The annual probability of exceedance for Nigeria showed no homogeneous trend as observed in the series of annual rainfall trend that showed critical anomaly of probability of exceedance of average peak at $20 \%$ (wet) in South-East, South-west, North central and North-west and $80 \%$ probability (dry) all the Northern region. It should be noted that though, excessive water reduces crop production as often as deficient water [33]. However, some other studies like that of [34] agreed that climate variations only explain a part of the yield variability and other factors, such as soil properties, management decisions (e.g., irrigation rate, fertilizer use) and market factors (e.g., fertiliser and energy prices) likely contribute to the remaining yield variations.

\subsection{CONCLUSION}

The study showed that annual rainfall varied in the six geopolitical regions with North-East having the lowest range and South-South area with highest. The average monthly rainfall exceedance at all part of Nigeria experienced rainfall more than $100 \mathrm{~mm}$ at all level of probability. The rainfall exceedance time series gave critical values of $20 \%$ and $80 \%$ in many of Nigeria during 
the study period and particularly dry occurrences of shorttime scales in Northern region while, wet exceedances occurrences for long time scales in South-East, SouthWest, North-Central and North-West. The study revealed periods of extreme rainfall of significant magnitude susceptible to crop failure in the different regions, if appropriate adaptation water conservation techniques through effective stakeholder collaboration is implemented to boost the crop production.

\section{REFERENCES}

[1] Onyenechere, E.C., Azuwike, D.O. and Enwereuzor, A.I. "Effect of Rainfall Variability on Water Supply in Ikeduru LGA of Imo State, Nigeria." African Research Review, 5(5), (2011), 223-241.

[2] Ekwe, M.C., Joshua, J.K., Igwe, J.E. and Osinowo, A. "Mathematical study of monthly and annual rainfall trends in Nasarawa State, Nigeria." IOSR J. Mathem, 10, (2014), 56-62.

[3] World Meteorological Organization. "Drought monitoring and early worming: concepts, progress and future challenges". $\mathrm{N}^{\circ} 1006$, (2006), 40-56.

[4] Bordi, I., Fraedrich, K. and Sutera, A. "Observed drought and wetness trends in Europe: an update". Hydrological Earth System Science, 13, (2009), 1519-1530.

[5] Vicente-Serrano, S.M., Begueria, S. and LopezMoreno, J.I. "A multi-scalar drought index sensitive to global warming: The Standardized Precipitation Evapotranspiration Index-SPEI". Journal of Climatology, 23, (2010), 1696-1718.

[6] Bevan, S.L, Los, S.O. and North, P.R.J. "Response of vegetation to the 2003 European drought was mitigated by height". Biogeosciences, 11(11), 2014, 2897-2908.

[7] Dettinger, M. and Cayan, D.R. "Drought and the California Delta - a matter of extremes". San Francisco Estuary and Watershed Science, 12(2), (2014).

[8] Falzoi, S, Acquaotta, F, Pulina, M.A, Fratianni S. Hydrological drought analysis in Continental Temperate and Mediterranean environment during the period 1981-2017. ItalianJournal of Agrometeorology, 3, (2019), 13-23. doi: 10.13128/ijam-798

[9] Van Loon, A.F. Hydrological drought explained. WIREs Water, 2(4), (2015), 359-392.

[10] Viste, E, Korecha, D and Sorteberg, A. Recent drought and precipitation tendencies in Ethiopia. Theoretical Applied Climatology, 112, (2012), 535-551.

[11] Lu, E., Luo, Y., Zhang, R., Wu, Q., and Liu, L. "Regional atmospheric anomalies responsible for the 2009- 2010 severe drought in China". Journal of Geophysical Research, 116, (2011), (D2114).

[12] Ronchi, C., Rabuffetti, D., Salandin, A., Vargiu, A., Barbero, S. and Pelosini, R. "Development of the Piedmont Region Hydrological Bulletin as a Support to Water Resources Monitoring and Management. In: Rossi G., Vega T., Bonaccorso B. (eds) Methods and Tools for Drought Analysis and Management. Water Science and Technology Library, 62, (2007).

[13] Capra, A. and Scicolone, B. "Spatiotemporal variability of drought on a short-medium timescale in the Calabria region (Southern Italy)". Theoretical. Applied Climatology, 116, (2012), 371-384.

[14] Kayano, M.T., and Sansígolo, C. "Interannual to decadal variations of precipitation and Daily maximum and daily minimum temperatures in Southern Brazil". Theoretical and Applied Climatology, 97, (2008), 81 - 90.

[15] Igwenagu, C.M. "Trend Analysis of Rainfall Pattern in Enugu State, Nigeria”. European Journal of Statistics and Probability, 3(3), (2015), 12-18.

[16] Olaniyi, O.A., Funmilayo, O.A. and Olutimehin, I.O. "Review of climate change and its effect on Nigeria ecosystem". International Journal of Environment and Pollution Research, 2(3), (2014), 70-81.

[17] Adejuwon, J.O. "Rainfall seasonality in the Niger Delta Belt, Nigeria”. Journal of Geography and Regional Planning, 5, (2011), 51-60. Available online at DOI: $10.5897 /$ JGRP11.096

[18] Odjugo, P.A.O. "General overview of climate change impacts in Nigeria", Journal of Human Ecology, 29(1), (2010), 47-55.

[19] Mina, M.H. and Sayedul, A. "Identifying the dependency pattern of daily rainfall of Dhaka station in Bangladesh using Markov chain and logistic regression model"'. Agricultural Sciences, 3(3), (2010), 385 - 391.

[20] Olaniran, O.J. "Rainfall Anomalies in Nigeria: The Contemporary Understanding". The FiftyFifth Inaugural Lecture of the University of Ilorin, (2002).

[21] Ayoade, J.O. "Introduction to Climatology for the Tropics”. Spectrum Books Limited, Ibadan, (2004), 258.

[22] Ikhilek, C.I., and Aifesehi, P.E.E. Geographical Distribution of Average Monthly Rainfall in the Western Section of Benin- Owena River Basin, Nigeria, African Reseach Review, 5(4), (2011), 493-500.

[23] Ogbo, A., Ndubuisi, E.L. and Ukpere, W. Risk Management and Challenges of Climate Change 
in Nigeria. Journal of Human Ecology, 41(3), (2013), 221-235.

[24] Agbaje, G.O., Saka, J.O., Adegbite, A.A. and Adeyeye, O.O. "Influence of agronomic practices on yield and profitability in kenaf (Hibiscus cannabinusL.) fibre cultivation". African Journal of Biotechnology, 7(5), (2016), 565 -574.

[25] Agnihotri, Y., Madukar, R.M., Singh, P. "Weekly rainfall analysis and agricultural drought at Charandigarh", Vayumandal, 16, (1986), 54-56.

[26] Ray, C.R., Senepati, P.C. and Lai, R. "Rainfall analysis for crop planning, Gaopalpur (Orissa)". Journal of Agricultural Engineering, 17, (1980), $1-8$.

[27] Gupta, R. A., Rambabu, A. and Tejwani, K.G. "Weekly rainfall of India for crop Planning programme", Soil Conservation Digest, 3, (1975), 31-39.

[28] Olesen, J. E. and Bindi. M. "The responses of agriculture in Europe to climate change". Regional Environmental Change, 11, (2011), 151-158

[29] Kurukulasuriya, P. and Rosenthal, S. Climate Change and Agriculture: A Review of Impactsand Adaptations. Climate Change Series. 94, (2013).

[30] Kashaigili, J., Levira, P.W., Liwemga, E.T. and Mdemu, M.V. "Analysis of Climate Variability,
Perceptions and Coping Strategies of Tanzanian Coastal Forest Dependent Communities". American Journal of Climate Change, 3(2), (2014), 212-222

[31] Bewket, W. "Rainfall variability and crop production in Ethiopia: case study in the Amhara region". Proceedings of the 16th International Conference of Ethiopian, 3, (2009), 823-836

[32] Elisabeth, V., Markus, G.D., Lisa, V. A., Malte, M., D. K., David, K., Nicolai, M. and Katja, F. (2019). "The effects of climate extremes on global agricultural yields". Environmental Research letter, 14(5), (2009), 054010.

[33] Hardjoamidjojo, S. and Skaggs, R. "Predicting the effects of drainage systems on corn yields". Agricultural Water Management, 5(2), (1982), 127-144.

[34] Friele, K., Lange, S., Piontek, F., Reyer, C.P.O. and Schewe, J. "Assessing the impacts of $1.5{ }^{\circ} \mathrm{C}$ global warming - simulation protocol of the InterSectoral Impact Model Intercomparison Project (ISIMIP2b)". Geoscientific Model Development 10, (2017), 4321-4345 